\title{
Nitric oxide metabolites in nasal lavage fluid of patients with house dust mite allergy
}

\author{
I M Garrelds, J G C van Amsterdam, C de Graaf-in't Veld, R Gerth van Wijk, \\ F J Zijlstra
}

Department of Pharmacology, Faculty of Medicine, Erasmus University, Rotterdam, The Netherlands I M Garrelds F J Zijlstra

Department of Allergology, University Hospital Rotterdam-Dijkzigt, Rotterdam, The Netherlands I M Garrelds C de Graaf-in't Veld $R$ Gerth van Wijk

Department of Pharmacology, RIVM, Bilthoven,

The Netherlands

J G C van Amsterdam

Reprint requests to: Dr I M Garrelds, Department of Pharmacology, Faculty of Medicine, Erasmus University Rotterdam, PO Box 1738 , PO Box 1738, 3000 DR Rotterdam
The Netherlands. Received 4 May 1994 Returned to authors 12 October 1994 Revised version received 20 October 1994 Accepted for publication 24 November 1994

\begin{abstract}
Background - The role of nitric oxide in the early and late phase of the allergic process was investigated in patients with allergic rhinitis against house dust mite and the effect of fluticasone propionate aqueous nasal spray was determined. Methods - Production of nitric oxide (measured as nitrite + nitrate) in vivo in nasal mucosa was examined in 24 patients with rhinitis allergic to the house dust mite. In a double blind placebo controlled crossover study fluticasone propionate $200 \mu \mathrm{g}$ aqueous nasal spray was administered twice daily for two weeks. In response to provocation with house dust mite extract (after four basal nasal lavages) nasal lavages were performed every hour for 9.5 hours by washing the nose with saline. In addition, a similar lavage protocol was performed in healthy volunteers with or without challenge with phosphate buffered saline.

Results - Nitric oxide is present in nasal lavage fluid in detectable amounts (range $10-50 \mu \mathrm{M})$, the level gradually increasing with time in both patients and controls after a decrease during the four basal lavages. Treatment with fluticasone propionate aqueous nasal spray did not affect initial basal production of nitric oxide nor production following provocation with house dust mite extract.

Conclusions - Production of nitric oxide in nasal mucosa determined in sequential nasal washings is not affected by therapeutic doses of intranasal steroids.

(Thorax 1995;50:275-279)
\end{abstract}

Keywords: nitric oxide, house dust mite, fluticasone propionate aqueous nasal spray.

House dust mites are the major cause of perennial rhinitis. The pathophysiology of allergic rhinitis, however, has been studied mainly in pollen allergy. ${ }^{1-3}$ To study the role of inflammatory mediators in ragweed pollinosis Naclerio et al developed a control model. ${ }^{4}$ After provocation with antigen mediators such as prostaglandin $\mathrm{D}_{2} \quad\left(\mathrm{PGD}_{2}\right)$, leukotriene $\mathrm{E}_{4}$ $\left(\mathrm{LTE}_{4}\right)$, tryptase, and histamine are released in the early phase of the allergic process, causing sneezing and rhinorrhoea. After a quiescent period a late phase occurs and symptoms recur when mediators are again released.4

It has recently been claimed that nitric oxide (NO) is an important mediator in bronchial inflammation. ${ }^{8-14}$ NO synthase (NOS) is the enzyme responsible for the generation of nitric oxide from L-arginine. The highly reactive and unstable nitric oxide rapidly decomposes to nitrogen oxides such as nitrite and nitrate. ${ }^{15}$ Nitric oxide synthase present in various cells from different (embryological) origin exists in two different forms ${ }^{16}$ - the constitutive, calcium dependent enzyme (cNOS) which releases nitric oxide after stimulation and the inducible, calcium independent enzyme (iNOS) which is found after induction with cytokines. ${ }^{15-17}$

The function of nitric oxide in the bronchoalveolar compartment may be either bronchodilatory (nitric oxide gas retains bronchodilating properties) or regulatory. Little is known of the regulatory function of nitric oxide.

In patients challenged with pollen antigens topical nasal steroids such as flunisolide reduce symptoms and mediator release in both the early and late phases of the allergic process. ${ }^{618}$ The corticosteroid fluticasone propionate has potent topical anti-inflammatory activity coupled with low systemic activity. ${ }^{1920}$

Our study design is based on the nasal challenge model developed by Naclerio $e t \mathrm{al}^{4}$ which enabled us to explore the role of nitric oxide in the early and late phase of the allergic process in patients with allergic rhinitis against house dust mites. The effect of fluticasone propionate aqueous nasal spray on the levels of nitrite + nitrate after nasal challenge with house dust mite extract was investigated and the effect of challenge with phosphate buffered saline on normal levels of nitrite + nitrate in healthy volunteers was determined.

\section{Methods}

HOUSE DUST MITE EXPERIMENT

Patients

The study was performed in 24 patients (13 men) of mean age 34 (range 21-50) years with a history of perennial rhinitis and skin reaction to house dust mite extract. All patients showed a skin reaction rated as at least one plus sign to 0.3 or 3 biological units $(\mathrm{BU}) / \mathrm{ml}$ extract according to the standardised plus sign scoring system defined by Norman. ${ }^{21}$ Six of the 24 patients were also allergic to grass pollen or animal epithelia. The nasal lavage experiments were performed between January and August to minimise exposure to house dust mites. The patients with a concomitant pollen allergy were tested outside the pollen season. None of the patients allergic to animals had pets in their home. Antihistamine drugs were withdrawn 72 hours before testing. The antihistamine astemizole, systemic corticosteroids, and topical 
corticosteroids were not used later than three weeks, two months, and three weeks respectively before the tests were performed. Patients who developed a nasal infection during the two weeks before the study were excluded. None had received immunotherapy.

The study was approved by the medical ethical committee of the University Hospital Rotterdam-Dijkzigt and all patients gave written informed consent.

\section{Nasal challenge and lavage}

After the positive skin test the subjects entered the double blind, placebo controlled, crossover phase of the study. Each underwent two allergen challenges performed after pretreatment with fluticasone propionate aqueous nasal spray (Glaxo, UK), $200 \mu \mathrm{g}$ twice daily for two weeks, or a placebo spray. A three week washout period separated the two challenges.

Before nasal challenge with house dust mite extract a nasal lavage was performed four times to obtain baseline mediator levels (b1-b4) by the method described by Naclerio et al. ${ }^{4}$ Both nostrils were washed with $5 \mathrm{ml}$ saline prewarmed to $37^{\circ} \mathrm{C}$. Lavage fluid was collected in plastic tubes and kept on ice. After centrifugation ( $10 \mathrm{~min}, 400 \mathrm{~g}$ ) supernatants of lavage fluids were stored at $-20^{\circ} \mathrm{C}$ until assay of nitric oxide. To prevent nasal congestion $0.25 \mathrm{ml}$ oxymetazoline $(0 \cdot 1 \%)$ was sprayed into each nostril five minutes before the first challenge. To obtain a control challenge $0.125 \mathrm{ml}$ phosphate buffered saline (PBS) was sprayed into each nostril and a nasal lavage was performed. For allergen challenge $0.125 \mathrm{ml}$ allergen extract was sprayed into each nostril and a nasal lavage was performed after 10 minutes. Allergen doses of 100,1000 , 10000 (h1-h3) biological units (BU)/ml (ALK, Groningen, The Netherlands) were administered. From 30 minutes up to 9.5 hours after the last challenge (time point $h 3$ ) the nasal washings were performed every hour by washing both nostrils with saline (s1-s10).

\section{Symptom score}

Symptoms were scored to study the correlation between clinical symptoms and production of nitric oxide as described by Lebel et al. ${ }^{22}$ The score was compiled before each lavage and after PBS and each allergen insufflation.

\section{CONTROL EXPERIMENTS WITH HEALTHY \\ VOLUNTEERS}

Two experiments were performed.

\section{Experiment 1: Nasal challenge with PBS and nasal lavage}

This experiment was performed in 11 healthy volunteers (six men) of mean age 31 (range 25-40) years. The same protocol as described above for patients was used, but instead of nasal challenges with house dust mite extract challenges with PBS were performed. From 30 minutes up to 7.5 hours after the last challenge (time point h3) the nasal fluid was obtained by washing the nose with saline.
Experiment 2: Nasal lavage without challenge This experiment was performed in six healthy volunteers (three men) of mean age 29 (range 25-41) years). The same protocol as for healthy volunteers described in experiment 1 was followed but without PBS challenge.

\section{Nitric oxide assay}

The nitric oxide metabolites nitrate (after reduction to nitrite) + nitrite were assayed colorimetrically after the Griess reaction as described by Phizackerly and Al-Dabbagh ${ }^{23}$ with the following modifications:

Collection and deproteinisation of samples: $200 \mu \mathrm{l}$ of nasal lavage fluid or standard was deproteinated by adding $20 \mu \mathrm{l} \mathrm{NaOH}(1.0 \mathrm{M}$, $4^{\circ} \mathrm{C}$; Merck, Germany) and $30 \mu \mathrm{l} \mathrm{ZnSO}_{4}$ (1.3 M, $4^{\circ} \mathrm{C}$; Merck, Germany). Samples were mixed and allowed to stand on ice for 15 minutes.

Conversion of nitrate to nitrite: After centrifugation $\left(5 \mathrm{~min}, 4^{\circ} \mathrm{C}, 2600 \mathrm{~g}\right) 100 \mu \mathrm{l}$ of the supernatant was mixed with $10 \mu \mathrm{l}$ Klebsiella pneumoniae suspension $(7.5 \mathrm{mg} / \mathrm{ml}$ protein), $20 \mu \mathrm{l} \quad 0.2 \mathrm{M} \mathrm{N}$-tris(hydroxymethyl)-methyl-2amino-ethane sulfonic acid (TES, $\mathrm{pH} 7 \cdot 0$; Sigma, USA), and $20 \mu \mathrm{l} 0.5 \mathrm{M}$ sodium formate (Merck, Germany). After anaerobic incubation at room temperature for 20 minutes $1.0 \mathrm{ml}$ water was added to the samples and nitrite was assayed in supernatants obtained by centrifugation ( $5 \mathrm{~min}, 2600 \mathrm{~g}$ ).

Estimation of nitrite: Deproteinised samples or standard $(200 \mu \mathrm{l})$ were mixed with $20 \mu \mathrm{l} 1 \%$ sulphanilamide (Sigma, USA) in 15\% phosphoric acid (Merck, Germany). After 10 minutes $20 \mu \mathrm{l} \quad 0 \cdot 1 \% \quad N$-(1-naphthyl)ethylenediamine (Sigma, USA) was added and the absorption at $540 \mathrm{~nm}$ was determined $(595 \mathrm{~nm}$ was used as a reference wavelength).

\section{STATISTICAL ANALYSIS}

Within patient totals over the two treatment periods were used to test equality of the carry over effect. Thirteen of the 24 patients received fluticasone propionate aqueous nasal spray during the first treatment period and 11 patients during the second treatment period. It was assumed that no significant carry over effect occurred if the means of these within patient totals were not significantly different in the two treatment groups. For this test a $p$ value of $<10 \%$ was considered significant. In case of a carry over effect, only the data of the first treatment period were used for statistical analysis. Values are expressed as means (SE).

Statistical analysis was performed with the non-parametric Mann-Witney U test (for comparison of placebo and fluticasone treatment) and the Wilcoxon unpaired test (for comparison between patients and controls).

\section{Results}

HOUSE DUST MITE EXPERIMENT Symptom score

Symptom scores are shown in the table. Because a significant carry over effect was ob- 


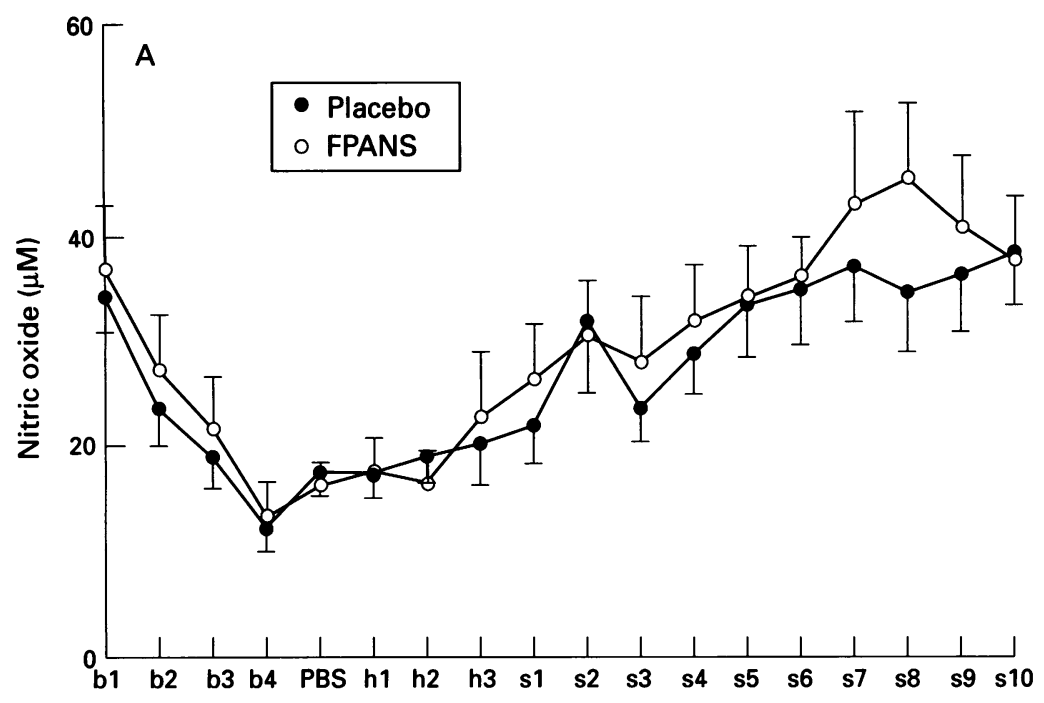

Mean (SE) symptom scores of patients allergic to house dust mite treated with placebo or with fluticasone propionate aqueous nasal spray

\begin{tabular}{lll}
\hline & Placebo & $\begin{array}{l}\text { Fluticasone } \\
\text { propionate }\end{array}$ \\
\hline Baseline & $0.67(0.19)$ & $0.29(0.13)$ \\
PBS & $2 \cdot 25(0.48)$ & $1.79(0.49)$ \\
h1 & $3.50(0.61)$ & $2.00(0.46)$ \\
h2 & $4.38(0.69)$ & $2.79(0.47)$ \\
h3 & $6 \cdot 17(0.63)$ & $3.67(0.51)$ \\
s1 & $3.58(0.55)$ & $2.00(0.41)$ \\
s2 & $2.13(0.41)$ & $1.04(0.28)$ \\
s3 & $1.54(0.37)$ & $0.71(0.19)$ \\
s4 & $1.00(0.30)$ & $0.35(0.14)$ \\
s5 & $1.04(0.36)$ & $0.26(0.14)$ \\
s6 & $1.58(0.39)$ & $0.22(0.13)$ \\
s7 & $1.71(0.44)$ & $0.30(0.13)$ \\
s8 & $1.63(0.47)$ & $0.48(0.23)$ \\
s9 & $1.79(0.45)$ & $0.48(0.19)$ \\
s10 & $0.71(0.25)$ & $0.22(0.13)$
\end{tabular}

$\mathrm{b}=$ baseline before challenge; $\mathrm{PBS}=$ lavage after challenge with phosphate buffered saline; h1, h2 and h3=lavages after challenge with 100,1000 , and 10000 biological units $(B U) / \mathrm{ml}$ house dust mite extract; $\mathrm{s} 1$-s10=lavages obtained every hour after the challenge with $10000 \mathrm{BU} / \mathrm{ml}$ house dust mite extract.

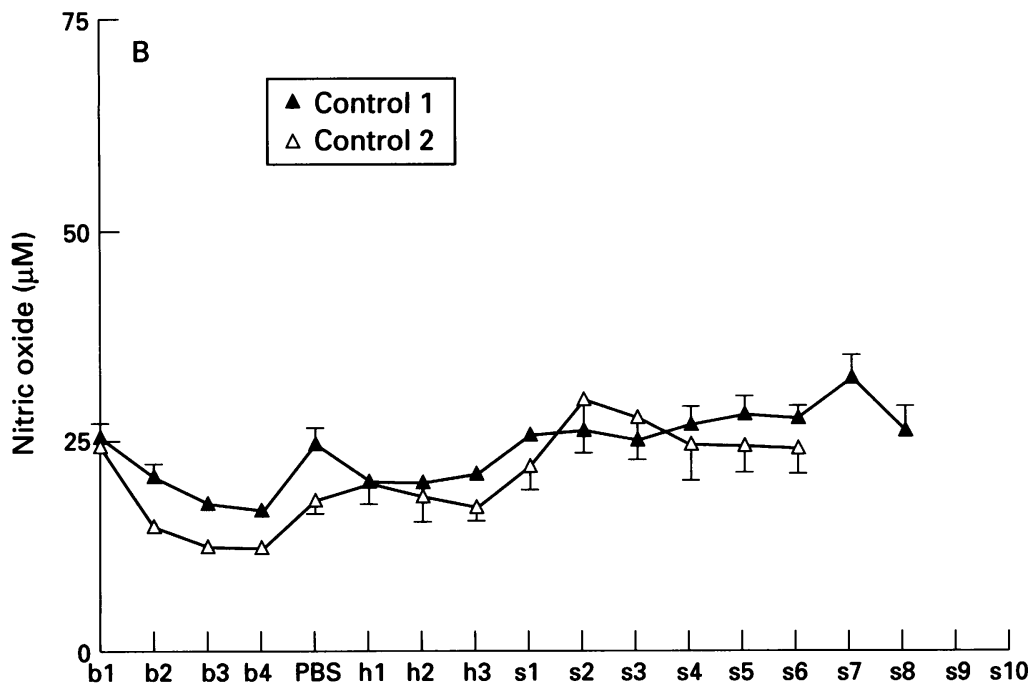

(A) Mean (SE) levels of nitric oxide in nasal lavage fluid of patients allergic to house dust mite treated with placebo or with fluticasone pmpionate aqueous nasal spray (FPANS). b1-b4=four basal lavages; PBS=lavage after challenge with phosphate buffered saline; h1, h2, and h3=lavages after challenge with 100, 1000, and 10000 $B U / m l$ house dust mite extract respectively; $s 1-s 10=$ lavages obtained every hour after the challenge with $10000 \mathrm{BU} / \mathrm{ml}$ house dust mite extract (time point h3). (B) Mean (SE) levels of nitric oxide in nasal lavage fluid of controls. b1-b4=four basal lavages, PBS, $h 1, h 2$ and $h 3=$ lavage after challenge with (control 1) or without (control 2) phosphate buffered saline; $s 1-s 10=$ lavages obtained every hour after time point $h 3$.

served, only the results of the first treatment period were used. A significant increase was observed immediately after the challenge with house dust mite extract in both groups. A late phase reaction occurred in both groups, after which the symptoms recurred. The symptom score of patients treated with fluticasone propionate aqueous nasal spray was significantly decreased in comparison with the placebo group at all time points examined.

Nasal nitric oxide levels

The levels of nitric oxide in nasal washings from patients allergic to house dust mite treated with fluticasone propionate aqueous nasal spray and with placebo are presented in the figure (part A). No significant carry over effect was observed but, because a significant carry over effect was observed for the symptom score, only the results of the first treatment period were used. The levels of nitric oxide decreased

significantly after the four basal washings. Nasal provocation with house dust mite extract caused no immediate release of nitric oxide but levels increased during the hours thereafter. No effect of fluticasone propionate on production of nitric oxide was observed in comparison with the placebo group, nor was there any effect on the nitric oxide content in the first lavage sample (b1).

\section{CONTROL EXPERIMENTS}

The levels of nitric oxide in nasal washings from healthy volunteers, with and without nasal challenge with PBS (figure, part B) were significantly decreased after the four basal washings. Nasal challenge with PBS caused no immediate release of nitric oxide but levels increased during the subsequent hours in controls both with and without PBS challenge.

\section{Discussion}

Lavage of the nasal mucosa after nasal challenge appears to be a convenient model for the determination of inflammatory mediator release during an allergic reaction to house dust mite. Exposure to the antigen in the nose triggers the formation of IgE antibodies which bind to receptors on several cells in the respiratory epithelium in the nasal cavities. These antibodies crosslink to the antigen, and inflammatory mediators such as histamine, tryptase, leukotriene $\mathrm{E}_{4}$, and eosinophil cationic protein are released. It has been suggested that the numbers of eosinophils and basophilic cells (basophils and mast cells) increase following allergen challenge and that this factor is responsible for the initiation of the allergic vascular response. ${ }^{2425}$

Our results show that nitric oxide (nitrite + nitrate) is detectable in nasal lavage fluid and shows little individual variation. Levels of nitric oxide decreased significantly during the first four basal lavages, indicating that nitric oxide present in the nostrils is washed out. Nasal challenge with house dust mite extract in patients with a history of perennial 
rhinitis caused no immediate synthesis of nitric oxide but the levels gradually increased during the hours after the challenge. A similar increase was also observed in the lavage fluid of the healthy volunteers, with or without challenge with PBS. Sequential nasal washings probably initiate migration of monocytes from the circulation to the nasal compartment or (re)activation of the monocytes present in the nasal mucosa. These monocytes may well be responsible for the gradual increase in endogenous nasal production of nitric oxide observed. Another possible explanation is plasma exudation of nitric oxide. In another study we have measured plasma levels of nitric oxide in healthy volunteers by the same method and have found levels of $24.5(3.4) \mu \mathrm{M}$.

In contrast, in the same 24 patients levels of albumin, tryptase, leukotriene $\mathrm{E}_{4}$, prostaglandin $\mathrm{D}_{2}$, and platelet activating factor increased immediately after provocation with house dust mite allergen (early phase reaction) and during the late phase reaction eosinophilic cationic protein was released. These mediators were inhibited by treatment with fluticasone propionate aqueous nasal spray. ${ }^{2627}$

Pretreatment of the patients with fluticasone propionate aqueous nasal spray twice daily for two weeks greatly reduces or prevents the major events in the allergic process - development of symptoms and release of inflammatory mediators. In a study performed in 17 atopic patients the immediate increase in nasal airway resistance was not inhibited by two weeks pretreatment with intranasal fluticasone propionate $200 \mu \mathrm{g} /$ day. $^{28}$ In another study the dose of ragweed required to produce a standardised response was unchanged after four weeks of treatment with intranasal fluticasone propionate $200 \mu \mathrm{g} /$ day in 49 patients during the ragweed season. ${ }^{29}$ However, in 24 patients with seasonal allergic rhinitis the symptom score was improved after nasal challenge with allergen after two and four weeks of pretreatment with fluticasone propionate. ${ }^{30}$ Long term treatment with intranasal fluticasone propionate was associated with a significant decrease in the number of nasal eosinophils, basophils, and neutrophils compared with placebo patients with seasonal allergic rhinitis. It has been proposed that fluticasone propionate may act by preventing activation of these cells and the subsequent release of (chemotactic) inflammatory mediators and further influx of cells. $^{28}$

Glucocorticoids are able to inhibit the induction of nitric oxide synthase in the lung in vivo after lipopolysaccharide treatment ${ }^{31}$ and they block the synthesis of nitric oxide in alveolar macrophages in vitro. ${ }^{32}$ Glucocorticoids inhibit induction of nitric oxide synthase in murine macrophages ${ }^{33}$ and the antiinflammatory effects of glucocorticoids could partly result from this inhibition.

In contrast to the above findings, we did not observe any effect of topically applied fluticasone propionate on production of nitric oxide in a crossover study in patients allergic to house dust mites. Both in patients and in controls nasal levels of nitric oxide gradually increased with time after a decrease during the four basal lavages.

Systemically applied glucorticoids may act by preventing activation of monocytes and the subsequent production of nitric oxide.

In conclusion, synthesis of nitric oxide can be monitored in nasal lavage fluid. Although intranasally applied fluticasone propionate aqueous nasal spray successfully reduced the allergen induced symptoms, the production of nitric oxide after challenge with house dust mite extract was not affected.

This study was supported by Glaxo BV, The Netherlands and by The Netherlands Asthma Foundation, Grant 32.92.74. The advice of Dr Paul G M Mulder of the Department of Epidemiology and Biostatistics on statistical methods is gratefully acknowledged.

Nasal challenges and lavages were performed at the Department of Allergology and the measurements of nitric oxide metabolites at the Department of Pharmacology, Erasmus Unimetabolites at the
versity Rotterdam.

1 Mosbech M. House dust mite allergy. Allergy 1985;40: 81-91.

2 Kern RA. Dust sensitization in bronchial asthma. Med Clin North Am 1921;5:751-8.

3 Voorhorst R, Spieksma-Boezeman MIA, Spieksma FThM. Is a mite (Dermatophagoides $\mathrm{sp}$ ) the producer of the housedust allergen? Allergie Asthma 1964;10:329-34.

4 Naclerio RM, Meier HL, Kagey-Sobotka A, Franklin-Adkinson N, Meyers DA, Norman PS, et al. Mediator release after nasal airway challenge with allergen. Am Rev Respir Dis 1983;128:597-602.

5 Naclerio RM, Proud D, Peters SP, Silber G, Kagey-Sobotka A, Adkinson Jr NF, et al. Inflammatory mediators in nasal secretions during induced rhinitis. Clin Allergy 1986;16: 101-10.

6 Naclerio RM. The pathophysiology of allergic rhinitis: impact of therapeutic intervention. $\mathcal{F}$ Allergy Clin Immunol 1988;82:927-34.

7 Van Toorenenbergen AW, Gerth van Wijk R, Vermeulen AM, Zijlstra FJ. Increase of albumin, eosinophil cationic protein, histamine, leukotrienes and mast cell tryptase in protein, histamine, leukotrienes and mast cell tryptase in
nasal lavage fluids after challenge with inhalent allergen nasal lavage fluids after challenge with inhalent allergen
extract. Agents Actions 1992;Special Conference Issue: C421-4.

8 Tucker JF, Brave SR, Charalambous L, Hobbs AJ, Gibson A. L-NG-nitroarginine inhibits nonadrenergic, noncholinergic relaxations of guinea-pig isolated tracheal smooth muscle. Br F Pharmacol 1990;100:663-4.

9 Li CG, Rand MJ. Evidence that part of the NANC-relaxant response of guinea-pig trachea to electrical field stimulation is mediated by nitric oxide. Br f Pharmacol 1991; 102:91-4.

10 Belvisi MG, Stretton CD, Verleden GM, Yacoub MH, Barnes PJ. Inhibitory NANC nerves in human tracheal smooth muscle: involvement of VIP and NO. Am Rev Respir Dis 1991;143:A355.

1 Dupuy PM, Shore SA, Drazen JM, Frostell C, Hil WA, Zapol WM. Bronchodilator action of inhaled nitric oxide in guinea-pigs. $f$ Clin Invest 1992;90:421-8.

12 Jorens PG, Vermeire PA, Herman AG. L-arginine-dependent nitric oxide synthetase: a new metabolic pathway in the lung and airways. Eur Respir 7 1993;6:258-66.

13 Barnes PJ. Neural mechanisms in asthma. Br Med Bull 1992;48:149-68.

14 Davies RJ, Devalia JL. Epithelia cells. Br Med Bull 1992; 48:85-96.

15 Moncada S, Palmer RMJ, Higgs EA. Biosynthesis of nitric oxide from L-arginine (a pathway for the regulation of cell function and communication). Biochem Pharmacol 1989; 11:1709-15

16 Moncada S, Palmer RMJ, Higgs EA. Nitric oxide: physiology, pathophysiology and pharmacology. Pharmacol Rev 1991;443:109-42.

17 Jorens PG, Van Overveld FJ, Bult H, Vermeire PA, Herman AG. L-arginine dependent production of nitrogen oxides by rat pulmonary macrophages. Eur $\mathcal{f}$ Pharmacol 1991; 200:205-9.

18 Pipkorn U, Proud D, Lichtenstein LM, Kagey-Sobotka A, Norman PS, Naclerio RM. Topical steroid pretreatment inhibits mediator release in vivo. $N$ Engl f Med 1987;316: inhibits med $1506-10$.

19 Phillips GH. Structure-activity relationships of topical active steroids; the selection of fluticasone propionate. Respir Med 1990;84(Suppl A): 19-23.

20 Bryson HM, Faulds D. Intranasal fluticasone propionate; a review of its pharmacodynamic and pharmacokinetic properties and therapeutic potential in allergic rhinitis. Drugs 1992;43:760-75.

21 Norman PS. Skin testing. In: Rose NR, Friedman H, eds. Manual of clinical immunology. 2nd edn. Washington: American Society for Microbiology, 1980:789-93.

22 Lebel B, Bousquet J, Morel A, Chanal I, Godard P, Michel FB. Correlation between symptoms and the threshold for release of mediators in nasal secretions during challenge 
with grass-pollen grains. F Allergy Clin Immunol 1988;82: 869-77.

23 Phizackerley PJR, Al-Dabbagh SA. The estimation of nitrate and nitrite in saliva and urine. Anal Biochem 1983;131: 242-5.

24 Pipkorn U, Karlsson G, Enerback L. The cellular response of the human allergic mucosa to natural allergen exposure. f Allergy Clin Immunol 1988;82:1046-54.

25 Howarth PH, Rajakulasingam K, Feather IH. Mediators and allergic rhinitis. Clin Exp Allergy 1991;21(Suppl 1):262-6.

26 Garrelds IM, De Graaf-in't Veld C, Jansen APH, Gerth van Wijk R, Zijlstra FJ. Effect of fluticasone propionate aqueous nasal spray treatment on platelet activating factor and eicosanoid production by nasal mucosa in patients with a house dust mite allergy. Mediators of Inflammation 1994;3:381-5.

27 De Graaf-in't Veld C, Garrelds IM, Jansen APH, van Toorenenbergen AW, Mulder PGH, Meeuwis J, et al. Effect of intranasal fluticasone propionate on the immediate and intranasal fluticasone propionate on the immediate and
late allergic nasal reaction and nasal hyperreactivity in patients with a house dust mite allergy. Clin Exp Allergy 1995 (in press).

28 Thomas KE, Greenwood L, Murrant N, Cook J, Devalia JL, Davies RJ. The effect of topical fluticasone propionate on allergen-induced immediate nasal airways response and eosinophil activation: preliminary results. RespirMed 1990; 84(Suppl A):33-5.

29 Small P, Biskin N, Barrett D. The effects of intranasal fluticasone propionate on allergen induced nasal provocation. Clin Invest Med 1989;12(Suppl 4):b5.

30 Juliusson S, Holmberg K, Karlsson G, Enerback L, Pipkorn $U$. Mast cells and mediators in the nasal mucosa after allergen challenge. Effects of four weeks' treatment with topical glucocorticoid. Clin Exp Allergy 1993;23:591-9.

31 Knowles RG, Salter M, Brooks SL, Moncada S. Antiinflammatory glucocorticoids inhibit the induction of nitric oxide synthase in the lung, liver and aorta of the rat. Biochem Biophys Res Commun 1990;172:1042-8.

32 Jorens PG, Van Overveld FJ, Bult H, Vermeire PA, Herman AG. Corticosteroids prevent the induction of nitric oxide synthase activity in different pulmonary cells. In: De Deyn PP, Marescau B, Stalon V, Qureshi I, eds. Guanidino compounds in biol.

33 Di Rosa M, Radomski M, Carnuccio R, Moncada S. Glucocorticoids inhibit the induction of nitric oxide synthase in macrophages. Biochem Biophys Res Commun 1990;172: 1246-52. 